\title{
Investigation and Analysis of Digital Resource Service of University Libraries Under the COVID-19 Epidemic
}

\author{
Chunyu Wang ${ }^{1}$ and Yingqi $\mathrm{Du}^{1, *}$ \\ ${ }^{1}$ The Library of Wuhan University of Technology, Wuhan, Hubei 430070, China \\ *Corresponding author Email: dyq@whut.edu.cn

\begin{abstract}
Taking the digital resource service of university libraries under the COVID-19 epidemic as the object of study, this paper aims to explore its content and ways in the case of major public health security emergencies, so as to improve the level of library service. In addition, this paper analyzes the contents of tweets of WeChat official account of "Double First-class" university libraries under the COVID-19 epidemic by adopting the data research method and content analysis method and discusses its existing problems under the COVID-19 epidemic. In view of the existing problems, this paper comes up with some suggestions for improving the digital resource service of university libraries: strengthening the integration and navigation of the external access mode of digital resources, refining the integration and push notification of digital resources, expanding the service mode of literature delivery and speeding up the construction of the electronic teaching reference system.
\end{abstract}

Keywords: digital resource, WeChat official account, COVID-19, university libraries

\section{INTRODUCTION}

The COVID-19 outbreak in Wuhan in early 2020 has become a major national public health emergency [1]. The Ministry of Education has issued a series of measures on prevention and control and made the deployment, made the decision to delay the opening of primary and secondary schools, and instructed all kinds of schools nationwide to carry out large-scale online education and teaching in the spring semester[2]. University libraries were closed temporarily. Teachers and students who carry out distance teaching and scientific research are highly dependent on network and digital resources, and the library service is facing unprecedented great challenges. Under the COVID19 epidemic, how should the library, as an auxiliary teaching unit in institutions of high learning, serve the teachers and students who "suspend classes without stopping learning"? What are the service measures of digital resources in university libraries since teachers and students who carry out distance teaching and scientific research are highly dependent on digital resources in libraries? How effective is the service? This paper investigates and analyzes the digital resource service of libraries in 42 "Double First-class" colleges and universities under COVID-19 from the aspect of digital resource service measures, response speed, service ability and service effect, explores the problems existing in the service and puts forward the suggestions for its improvement with the hope of providing reference for digital resources services in university libraries.

\section{DESIGN OF RESEARCH SCHEME}

\subsection{Research Object and Content}

With the rapid development of the Internet, WeChat has become one of the most popular information exchange platforms. According to WeChat Data Report in 2019, WeChat monthly active users have reached 1.151 billion by September 2019 [3]. Under the COVID-19 epidemic, physical libraries were closed, and university libraries used WeChat official accounts to provide library services to readers. Therefore, we can, to a certain extent, reveal the service contents and methods of university libraries by exploring and analyzing the tweets from their WeChat official account during the COVID-19 epidemic [4].

The WeChat official accounts of 42 "Double First-class" university libraries announced by the Ministry of Education, the Ministry of Finance, and the National Development and Reform Commission were selected as the research objects, and the content and number of articles were statistically analyzed. The research content includes the total number of tweets on WeChat official account and the number of tweets related to digital resource service, the response of digital resource service by libraries to this emergency, and the digital resource service, etc. 


\subsection{Research Method and Time Frame}

Through the "search" function of mobile version WeChat, we searched for the effective WeChat official accounts corresponding to 42 university libraries, collected and read the aritcles of each WeChat official account, and screened out the articles related to the e-teaching materials service. The data collection period is from January 23, 2020 (when Wuhan was closed) to April 8 (when Wuhan was opened), a total of 76 days.

\section{Research RESULTS AND ANALYSIS}

During the period of data collection, the number of tweet of WeChat official account of the library of Beijing Institute of Technology is 0 , and the Wechat official account of the library of China Agricultural University has 1 tweet. These two libraries are not included in the statistical analysis. Table 1 shows the digital resource services of "Double First-class" university libraries under the COVID-19 epidemic.

Table 1 The list of digital resource services in "Double First-class" university libraries under the COVID-19 epidemic

\begin{tabular}{|c|c|c|c|c|c|c|c|c|c|c|c|}
\hline Name of the university library & 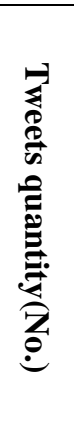 & 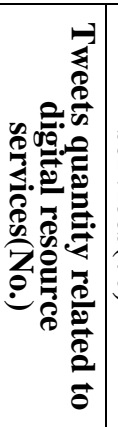 & 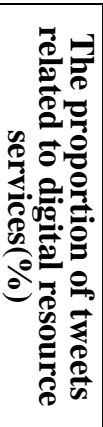 & 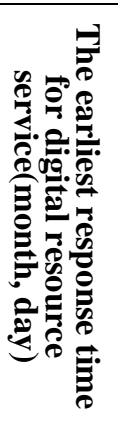 & 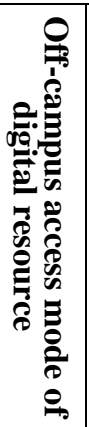 & 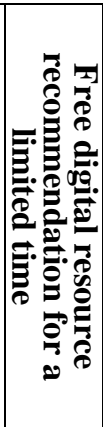 & 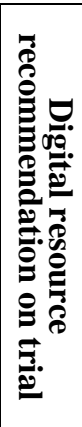 & 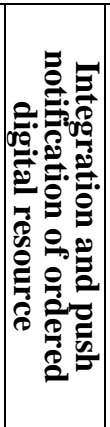 & 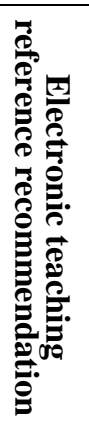 & 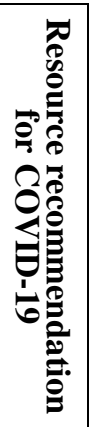 & 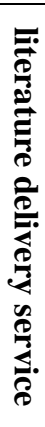 \\
\hline Peking University Library & 54 & 39 & 72 & 1.31 & $\checkmark$ & $\checkmark$ & $\checkmark$ & $\checkmark$ & $\checkmark$ & $\checkmark$ & $\checkmark$ \\
\hline Tsinghua University Library & 71 & 45 & 63 & 1.28 & $\checkmark$ & $\checkmark$ & $\checkmark$ & $\checkmark$ & $\checkmark$ & $\checkmark$ & $\checkmark$ \\
\hline Renmin University of China Library & 58 & 30 & 52 & 1.24 & $\checkmark$ & $\checkmark$ & $\checkmark$ & $\checkmark$ & $\checkmark$ & $\checkmark$ & $\checkmark$ \\
\hline $\begin{array}{c}\text { Beijing University of Aeronautics and } \\
\text { Astronautics Library }\end{array}$ & 32 & 29 & 91 & 2.01 & $\checkmark$ & $\checkmark$ & & & $\checkmark$ & & \\
\hline Beijing Normal University Library & 87 & 36 & 41 & 1.29 & $\checkmark$ & & $\checkmark$ & $\checkmark$ & $\checkmark$ & & $\checkmark$ \\
\hline Minzu university of China Library & 46 & 22 & 48 & 2.01 & $\checkmark$ & $\checkmark$ & $\checkmark$ & $\checkmark$ & 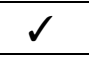 & $\checkmark$ & \\
\hline Nankai University Library & 104 & 39 & 38 & 1.28 & $\checkmark$ & $\checkmark$ & $\checkmark$ & $\checkmark$ & $\checkmark$ & $\checkmark$ & $\checkmark$ \\
\hline Tianjin University Library & 196 & 49 & 25 & 1.27 & $\checkmark$ & $\checkmark$ & $\checkmark$ & $\checkmark$ & $\checkmark$ & & $\checkmark$ \\
\hline Dalian University of Technology Library & 43 & 22 & 51 & 2.01 & $\checkmark$ & $\checkmark$ & & $\checkmark$ & $\checkmark$ & $\checkmark$ & $\checkmark$ \\
\hline Jilin University Library & 96 & 58 & 60 & 1.29 & $\checkmark$ & $\checkmark$ & $\checkmark$ & 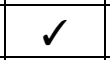 & $\checkmark$ & $\checkmark$ & \\
\hline Harbin University of Technology Library & 33 & 15 & 45 & 1.31 & $\checkmark$ & $\checkmark$ & & $\checkmark$ & $\checkmark$ & & \\
\hline Fudan University Library & 63 & 20 & 32 & 1.29 & $\checkmark$ & $\checkmark$ & $\checkmark$ & $\checkmark$ & $\checkmark$ & $\checkmark$ & $\checkmark$ \\
\hline Tongji University Library & 27 & 8 & 30 & 2.03 & $\checkmark$ & $\checkmark$ & $\checkmark$ & & & & \\
\hline Shanghai Jiaotong University Library & 63 & 40 & 63 & 1.29 & $\checkmark$ & $\checkmark$ & $\checkmark$ & $\checkmark$ & $\checkmark$ & $\checkmark$ & $\checkmark$ \\
\hline East China Normal University Library & 79 & 33 & 42 & 2.01 & $\checkmark$ & $\checkmark$ & $\checkmark$ & $\checkmark$ & $\checkmark$ & $\checkmark$ & $\checkmark$ \\
\hline Nanjing University Library & 56 & 29 & 52 & 1.31 & $\checkmark$ & $\checkmark$ & $\checkmark$ & $\checkmark$ & & & $\checkmark$ \\
\hline Southeast University Library & 65 & 24 & 37 & 2.06 & $\checkmark$ & $\checkmark$ & $\checkmark$ & $\checkmark$ & $\checkmark$ & & $\checkmark$ \\
\hline Zhejiang University Library & 75 & 30 & 40 & 1.30 & $\checkmark$ & $\checkmark$ & $\checkmark$ & $\checkmark$ & $\checkmark$ & & $\checkmark$ \\
\hline $\begin{array}{c}\text { University of Science and Technology of } \\
\text { China Library }\end{array}$ & 39 & 20 & 51 & 1.28 & $\checkmark$ & $\checkmark$ & $\checkmark$ & $\checkmark$ & $\checkmark$ & & $\checkmark$ \\
\hline Xiamen University Library & 72 & 27 & 38 & 2.01 & $\checkmark$ & $\checkmark$ & $\checkmark$ & $\checkmark$ & $\checkmark$ & & $\checkmark$ \\
\hline Shandong University Library & 71 & 18 & 25 & 2.05 & $\checkmark$ & $\checkmark$ & & $\checkmark$ & $\checkmark$ & & $\checkmark$ \\
\hline China Ocean University Library & 28 & 22 & 79 & 2.06 & $\checkmark$ & $\checkmark$ & $\checkmark$ & $\checkmark$ & & $\checkmark$ & $\checkmark$ \\
\hline Wuhan University Library & 69 & 15 & 22 & 2.06 & $\checkmark$ & $\checkmark$ & & $\checkmark$ & $\checkmark$ & $\checkmark$ & \\
\hline $\begin{array}{c}\text { Huazhong University of Science and } \\
\text { Technology Library }\end{array}$ & 24 & 9 & 38 & 2.03 & $\checkmark$ & $\checkmark$ & & & $\checkmark$ & & \\
\hline
\end{tabular}




\begin{tabular}{|c|c|c|c|c|c|c|c|c|c|c|c|}
\hline Central South University Library & 36 & 15 & 42 & 2.04 & $\checkmark$ & $\checkmark$ & $\checkmark$ & $\checkmark$ & $\checkmark$ & & \\
\hline Sun Yat-sen University Library & 120 & 49 & 41 & 2.03 & $\checkmark$ & $\checkmark$ & $\checkmark$ & $\checkmark$ & $\checkmark$ & $\checkmark$ & $\checkmark$ \\
\hline $\begin{array}{c}\text { South China University of Technology } \\
\text { Library }\end{array}$ & 56 & 18 & 32 & 2.01 & $\checkmark$ & $\checkmark$ & & $\checkmark$ & $\checkmark$ & $\checkmark$ & $\checkmark$ \\
\hline Sichuan University Library & 19 & 9 & 47 & 2.06 & $\checkmark$ & $\checkmark$ & & & $\checkmark$ & & \\
\hline Chongqing University Library & 16 & 7 & 44 & 2.03 & $\checkmark$ & & & $\checkmark$ & $\checkmark$ & $\checkmark$ & \\
\hline $\begin{array}{c}\text { University of Electronic Science and } \\
\text { Technology }\end{array}$ & 38 & 12 & 32 & 2.01 & $\checkmark$ & $\checkmark$ & $\checkmark$ & $\checkmark$ & $\checkmark$ & & \\
\hline Xi'an Jiaotong University Library & 35 & 15 & 43 & 2.11 & $\checkmark$ & $\checkmark$ & $\checkmark$ & & $\checkmark$ & $\checkmark$ & $\checkmark$ \\
\hline $\begin{array}{c}\text { Northwest Polytechnic University } \\
\text { Library Library }\end{array}$ & 46 & 20 & 43 & 2.03 & $\checkmark$ & $\checkmark$ & & & $\checkmark$ & $\checkmark$ & \\
\hline Lanzhou University Library & 160 & 102 & 64 & 1.30 & $\checkmark$ & $\checkmark$ & $\checkmark$ & $\checkmark$ & $\checkmark$ & $\checkmark$ & $\checkmark$ \\
\hline $\begin{array}{c}\text { National University of Defense } \\
\text { Technology Library }\end{array}$ & 41 & 12 & 29 & 1.29 & $\checkmark$ & $\checkmark$ & $\checkmark$ & $\checkmark$ & $\checkmark$ & & \\
\hline Northeast University Library & 68 & 29 & 43 & 1.30 & $\checkmark$ & $\checkmark$ & & $\checkmark$ & $\checkmark$ & $\checkmark$ & $\checkmark$ \\
\hline Zhengzhou University Library & 66 & 38 & 58 & 1.30 & $\checkmark$ & $\checkmark$ & $\checkmark$ & $\checkmark$ & $\checkmark$ & $\checkmark$ & $\checkmark$ \\
\hline Hunan University Library & 60 & 32 & 53 & 1.30 & $\checkmark$ & $\checkmark$ & & $\checkmark$ & $\checkmark$ & $\checkmark$ & $\checkmark$ \\
\hline Yunnan University Library & 81 & 55 & 68 & 1.29 & $\checkmark$ & $\checkmark$ & $\checkmark$ & & $\checkmark$ & $\checkmark$ & \\
\hline $\begin{array}{c}\text { North West Agriculture and Forestry } \\
\text { University Library }\end{array}$ & 22 & 10 & 45 & 2.13 & $\checkmark$ & $\checkmark$ & $\checkmark$ & & & & \\
\hline Xinjiang University Library & 56 & 13 & 23 & 1.29 & $\checkmark$ & $\checkmark$ & & $\checkmark$ & $\checkmark$ & $\checkmark$ & \\
\hline Total & 2471 & 1115 & 45 & & & & & & & & \\
\hline
\end{tabular}

From above table, we can see that digital resource service was provided during the COVID-19 in libraries and tweets related to digital resource service accounted for $45 \%$, which reflects that university libraries actively responded to the outbreak, introduced a variety of forms of digital resources service, tried their best to meet the requirements of teachers and students on literature resources in scientific research and teaching and guaranteed to provide the literature resources. There were 13 libraries with more than $50 \%$ tweets for digital resource services, 13 libraries with less than $40 \%$ tweets, and 14 libraries with $40-50 \%$ tweets.

During the COVID-19 epidemic, the libraries' digital resource services mainly include the following six fields: the first one is the service of off-campus access to library digital resources, which is provided by $100 \%$ of libraries. During the epidemic prevention and control period, the demand of teachers and students to access to electronic resources outside the campus has increased dramatically. In order to ensure that teachers and students can use digital resources more conveniently and efficiently outside the campus, university libraries, together with network and information centers and each database provider, have developed various remote access methods. The main ways to access to library digital resources off-campus include school VPN, CARSI certification, remote access tool based on Myloft, proxy server, Bras off-campus dialing method, short-term off-campus roaming (through domain email registration), etc. The second is the free digital resource recommendation. $95 \%$ of the libraries actively collect relevant information, sort out, inform and notify free data base during the epidemic period, such as Vip Information, Wanfang data, MyET English multimedia resource base, etc. $66 \%$ libraries also actively mobilize some databases to open their database on a trial basis to provide more academic resources for teachers and students. The third is integrating and pushing digital resources ordered, which is provided by $78 \%$ of libraries. In order to facilitate readers to quickly find the resources they need, the digital resources ordered by libraries are classified and integrated according to disciplines and literature types. For example, during the epidemic period, the library of Shanghai Jiao Tong University integrated and pushed digital resources ordered by nine disciplines according to the classification of periodicals, foreign ebooks and Chinese e-books. The fourth is the service of electronic teaching reference resource, which is provided by $88 \%$ of libraries. Faced with the rigid demand of teachers and students for e-teaching materials who "suspend classes without stopping learning", university libraries have launched various forms of e-teaching services to solve the problem of the shortage of e-teaching materials in distance teaching, ensure the resources of eteaching materials and facilitate online teaching. The fifth is to integrate and push resources of COVID-19-related topics, which is provided by $56 \%$ of libraries. Libraries take advantage of their expertise to collect and push notification of the latest academic resources related to COVID-19 at home and abroad, and provide special services for researchers to carry out research on COVID19 and apply related topics, so as to contribute to the initiative of keeping research on the epidemic. The sixth is 
to offer free literature delivery services, which is provided by $59 \%$ of libraries. Literature delivery service is a service method adopted by library information and related organizations to meet the real-time needs of users and improve service efficiency under the network environment. During the special period of epidemic prevention and control, the initiative of "non-stop study and research" made university libraries to strengthen the publicity and service of literature delivery. For example, Peking University Library has increased the subsidy for literature delivery service and implemented $100 \%$ subsidy.

\section{PROBLEMS IN DIGITAL RESOURCE SERVICES}

Under the COVID-19 epidemic, "Double First-class" university libraries have taken active actions and innovated their service in providing digital resource services. However, due to the actual situation and the sudden outbreak of the epidemic, there are still some problems in digital resource services.

\subsection{Digital Resource Service is Lagged Behind}

On January 23, 2020, Wuhan announced the closure of the city, and the epidemic prevention and control in the whole country was upgraded. University libraries successively issued notices of closure and postponement of opening. Only $48 \%$ of libraries responded with digital resource services within a week, and $33 \%$ had digital resource services only 10 days after the outbreak began. It can be seen that the overall digital resource service of the library is lagged behind.

\subsection{Insufficient Guidance for Off-campus Access to Digital Resources}

It can be seen from the survey that most libraries provide a variety of ways to access to digital resources off-campus, which reflects the importance of this service. However, there are some problems, such as unclear introduction of access to the service. Most libraries simply introduce several off-campus access methods, entrances and steps, but do not make clear which kinds of access methods can be used for each database and which methods are better, which is inconvenient for readers to use.

\subsection{The Integration and Push Notification of Digital Resource is Not Refined Enough}

After analyzing the content of digital resource tweets, it is found that there are two forms of free push notification of digital resource for libraries. One is to directly push notification of the collected free resources to readers either individually or by listing and summarizing them. The other is to provide the information to teachers and students according to literature, subject or special topic. Only a few libraries carry out the second kind of service which has more refined classification, integration and push notification, so that teachers and students can get the required resources in a more targeted way. It can be seen that free resource push notification is not refined enough.

\subsection{The Service of Electronic Teaching Reference is Not Accurate Enough}

It can be seen from the survey results that $82.5 \%$ of the libraries recommended free teaching reference resources for a limited time, trial teaching reference resources and subscribed database to teachers and students. There are the following problems in these three service modes: first, readers can only access to part of the electronic version of teaching materials, but most of the teaching materials cannot be accessed to; second, the teaching reference resources opened for a limited time are too fragmented, which are full of various web pages and public accounts. Although libraries push notification to readers by collecting and sorting out information, the methods of obtaining them are complicated: some need account passwords, some need to install apps, and some need registration and authentication. Third, there is no retrieval function. Teachers and students cannot access to the electronic textbook teaching reference in a direct, convenient and fast way. These three service modes do not conform to the principle of "precise service" of the library [5]. The service of the library should be refined and more standardized.

\section{SUGGESTIONS FOR IMPROVEMENT OF DIGITAL RESOURCE SERVICE}

In view of the existing problems in the digital resource service of university libraries under the COVID-19 epidemic, combined with the service measures and practical exploration by some libraries, it is suggested to improve the service from the following aspects.

\subsection{Strengthen the Integration and Navigation of Access Mode of Digital Resources Off- campus}

First of all, it should optimize the configuration of exit and database access path of different network applications to cope with the constant changes of network infrastructure, so as to provide readers with a variety of ways to access to library digital resources off-campus. Then, relevant guidance services should be provided to help readers quickly understand and learn how to access to library digital resources off-campus. The library should comprehensively summarize and integrate off-campus access mode from the perspective of readers, and provide 
clear guidance for readers, such as illustrated use guides, short and easy to understand micro-videos, concise and clear F\&Q and small programs with strong operability, etc., to explain and recommend access mode.

\subsection{Integrate and Push Notification of Digital Resources in a More Refined Way}

For ordering digital resources, it should push notification in a "theme-based" manner according to the characteristics of school disciplines and the needs of readers, so as to strengthen the construction of the library's official website database navigation and unified retrieval platform. It should integrate and push notification of free digital resources in accordance with subjects, literature and related topics, add free resources to the digital resource navigation on the official website of the library, and set up a special column of free resources on WeChat official account of the library to well display navigation and make a clear introduction.

\subsection{Expand the Ways of Literature Delivery Service}

With the development of network informatization, digital resource service has entered a new era. A single library can't collect all the digital resources required by teachers and students of universities. Literature delivery is the best supplement to digital resource service. Literature delivery can break through traditional forms. For example, a "literature mutual help group" (QQ or WeChat) can be set up, and library staff can provide services according to the literature resource demands put forward by readers in the group. In the case of emergencies such as COVID-19, literature delivery can deliver the existing resources of libraries, providing convenience for teachers and students who are not able to access the digital resources of libraries outside campus.

\subsection{Speed Up the Construction of an Electronic Teaching Reference System}

The guarantee of electronic teaching resources is an important embodiment of the universities' library as one of the three pillars of teaching and research in China's institutions of high learning. Large-scale online teaching during the epidemic highlights the importance of systematic teaching reference resource service, which is an important way to realize systematic teaching reference resource service. In addition to collecting and integrating free and trial teaching resources, libraries should pay more attention to the construction of an electronic teaching resources system, which can not only be an emergency measure in case of emergencies but also be a regular service mechanism. At the same time, the electronic teaching reference system and the school teaching system should be integrated so as to share learning and docking services and form a teaching ecosystem with seamless links of resources, personnel and technologies [6].

\section{CONCLUSION}

What are the digital resource services provided by university libraries under COVID-19? How effective are these services? How will the digital resource service by libraries be carried out in the future when encountering major health security incidents similar to COVID-19? Through the survey of WeChat tweets of "Double Firstclass" university libraries under COVID-19, this paper finds that there are some problems in university libraries under COVID-19, such as belated digital resource service, insufficient guidance of off-campus access mode, insufficient refinement of integration and push notification of resources, and inaccurate e-teaching reference service. On the basis of investigation and analysis, from the perspective of necessity and feasibility of digital resources services in university libraries, this paper comes up with suggestions for improving digital resource service: strengthening digital resources integration and navigation of off-campus access mode, refining its integration and push notification, expanding the way of literature delivery service, and speeding up the construction of teaching reference system.

\section{REFERENCES}

[1] Ke Ping, "Discussion on library emergency service mechanism during public security emergencies," Library Journal, vol. 39, no.03, pp. 8-10, 2020. DOI: https://doi.org/10.13663/j.cnki.lj.2020.03.001

[2] Ministry of Education of the People's Republic of China, "Notice on the postponement of the spring semester of 2020," [EB/OL]. [2020-01-27]. http://www.moe.gov.cn/jyb_xwfb/gzdt_gzdt/s5987/202 001/t20200127_416672.html.

[3]2019Wechat Data Report, [EB/OL].http://mp.weixin.qq.com/s/vmhosRzpBs7JK_x2a7gZw.

[4] Wu Jinhui, "Analysis of service innovation of universities libraries based on the articles content of WeChat official account," Information Research, no. 12, pp. 103-108, 2018. DOI:

https://doi.org/10.3969/j.issn.1005-8095.2018.12.019

[5] Wen Hanrong, "Thinking on integrating academic instruction \& reference service into library service," Information Research, no. 04, pp: 119-121, 2015. DOI: https://doi.org/10.3969/j.issn.1005-8095.2015.04.031 
[6] Wang Bo, Zhou Chunxia, Chen Ling, “Actively integrate into the overall situation of COVID-19 epidemic's prevention and control and practically innovate the service strategy during extraordinary and control and practically innovate the service strategy during extraordinary period", Journal of Academic Libraries, vol. 38, no.02, pp. 5-17+29, 2020. DOI: https://doi.org/10.16603/j.issn1002-1027.2020.02.001 